\title{
Effect Of Mainstreaming Education On The Academic Achievement Of Mildly Impaired Lower Basic Three Pupils In Northwest Nigeria
}

\author{
${ }^{1}$ Aminu Kazeem Ibrahim (PhD) \& ${ }^{2}$ Fidel O. Okopi (PhD). \\ ${ }^{1,2}$ National Open University of Nigeria, Victoria Island, Lagos.
}

\begin{abstract}
The study investigated the effect of mainstreaming education onthe English language, Mathematics and Social studies academic achievement of mildly impaired pupils in northwest Nigeria. Ex-post facto research design was adopted for the study. The sample consisted of 2443 mildly impaired lower basic three pupils who were identified by classroom teachers with the use of Prevalennce of Varied mildly Impairements / Disabilities and Academic Achievement Scale and 2443non-impaired pupilsrandomlly selected from five public lower basic three secondary schools in seven states in northwest Nigeria. Data for the study were collected with an instrument 'Prevalence of Varied Mild Impairments/Disabilities and Academic Achievement Scale (POVMIDAAS). Methods of validation include: face, content and score transformation. Independent sample $t-$ test and one way analysis of variance were used to analyze the hypotheses at 0.05 level of significance. The results shows that there is a significant difference betweenthe English language academic achievement;; Mathematics academic achievemnt; Social Studies academic achievemet; and English language, Mathematics and Social Studies academic achievements of mildly impaired and non- impaired pupils in northwest Nigeria. The paper recommends that specialists in the education of mildly impaired pupils (pupils that has mild visual, hearing, speech / language, learning and behaviour) should be employed. Teachers should employed varied teaching methods and strategies to accormondate the various categories of pupils when teaching and teachers should also help the impaired pupils to reassess as well as reinforce thier goals, values and assets as well as reinforce thier efforts for better adjustment.
\end{abstract}

Key words: Mainstreaming Education Academic Achievement, Mildly Impaired Pupils, Non-impaired Pupils, Northwest Nigeria.

\section{Introduction}

The Nigeria National Policy on Education (2004) recommends mainstreaming, inclusive or integration of special classes and units into ordinary / public schools under the Universal Basic Education Scheme. This approach is the practice of educating handicapped persons / pupils together with thier non-handicapped peers in the same regular school environment. The main aim of this arrangement is to provide equal educational opportunities and also help in the realization of the national objectives of giving concretemeaning to the idea of equalising educational opportunities for all children and adults, physically, sensory, mental, psychological or emotional disabilities notwithstanding ; provide adequate education for all people with special needs in order that they may fully contribute thier own quota to the development of Nigeria nation provide opportunities for exceptionally gifted and talented children to develop thier talents, natural endowments / traits at thier own pace in the interest of the nations economic and technological development and design a diversify an appropriate curriculum for all the beneficiaries (N.P.E., 2004). The mainstreaming Education in Nigeria particularlly, in northwest Nigeria is not very clear becuase the same National Policy on Education that recommends mainsreaming education also defines special education as the education of children and adults who have learning difficulties because of different kinds of handicaps-blindness, partial-sightedness, deafness, hardiness of hearing, mental retardation, social -maladjustment, limb defromity or malformation etc, due to circumstances of birth, inheritance, social position, mental and physical health patterns, or accident in later life. It goes on further to say that there are also the specially gifted and talented children who are intellectually precocious and find themselves insufficiently challenged by the programmes of the regular school (N.P.E., 2004).

Scholars and stakeholder has continue to react in different ways to these two diverse idea and practice; some are in support and others against the policy of mainstreaming education. For example, many scholars in the field of special education, educational psychology and other similar areas continue to express fear on what will be the outcome of such an arrangement. For instance, Igwe (2003) opines that adolescents in mainstreaming education has many problems arising from physiological make-up, generation gap and sexuality. Adam (2009) opines that if investigations are conducted on the effect of mainstreaming education in Nigeria, a lot of revealations that will come out will make the architect of such arrangement to have a rethink on the idea. Olaleye (2010) strongly condems the idea of integration of handicapped children with normal chldren and 
concludes that the arrangement was adopted by government only to reduce cost of public spending on the education of handicapped children which requireshuge investiment. The handicapped (mildly impaired pupils) are confronted with more than these problems because of handicapped conditions.

According to Dada (2008) exceptional pupils are unable to engage in all activities open to thier nonexceptional peers and these usually contributes to poor academic performance. In the same view, Howard (2004) cautionthat mainstreaming education slowed down the bandwagon of instant change and the confusion between civil right and the right kind of education for every child. Nwokolo (2003) opines that successful uses of academic achievement records has be used to classify adjusted and non-adjusted adolescents. Abu (2011) believes that academic achievement records can be analyze to identify groups that are unequal based on predetermined criterion. Adepoju (2012) observes that a well documented academic achievement records of scores of learners' are used to determine the success or failure of many educational programmes and policies in many parts of the world. Bichi (2009) opines that one of the most known formal criterial for evaluating whether learning as taken place among learners' is through the uses of academic performances and achievements. Yusuf (2012) believes that proper adjustment and successful academic achievement among learners' are indicators of successful teaching and learning. Smith (2010) cautions that when using academic achievement to differenciate between groups and therefore, advocates the use of combinations of differenct academic records that shows variations among learners. Igwe (2003); Abang (1986) and Igboayaka (1986) observes that the negative atitude of the non-impaired pupils to the impaired pupils is one of the causes of self-esteem of the impaired pupils commonlly found in mainsreaming education.

The practice of mainstreaming / integration education is spread among puplic schools in northwest zone of Nigeria.The arrangement in this zone involves educating mild visually impaired pupils who are identified with frequent bumping into objects, reversing letters, holding object too close to the eyes, awkward in games requiring eyes and hand coordinations, frequent pus on the eyes, rub or brush eyes frequently, redness of the eyes. Hearing impaired who frequently have limited ability to hear sound, non-response when talked to, difficulty in language, asking for repetition of questions, cupping the ear in order to hear better, straying to hear, lessened laughter, screaming to express pleasure, annoyance or need, stamping of foot for vibratory sensation. Speech and language disorders who frequently have omission of first sounds in words, inability to make complete sentences, repetition or prolongation of sounds and syllables, delayed language development, articulation disorders and voice disorders, uses of unintelligible speech. Learning disabled who are frequently hyperactive or restless, perpetual motor impairment, emotional problems such as up and down anxiety, general coordination deficit such as poor hand-eyes and head-hand coordination, disorder of memorythinking, specific academic problems in reading, writting, spelling, arithmetics, disorder of speech and learning, mistakes in identifying left and right. And, behaviour disorders who frequentlly withdraw, excessive crying, fighting, stealing, destroying of properties, depressed. The fear is that, the approach is left uncheck, it will cause more harm than good. This study therefore, investigates theeffect of mainstreaming education on the English language, Mathematics and Social studies academic achievement of mildly impaired lower basic three pupils in Northwest, Nigeria.

\section{Statement of the Problem}

The study is designed to investigate the effect of mainstreaming education on the academic achievement of mildly impaired pupils in northwest Nigeria. This became necessary by the persistent fear by school administrators, parents / guidian, teachers and otherstakeholders that mainstreaming education operating in the zone is causing more harm and is not contributing to the positive and desired academic performaces and adjustment of the exceptional pupils. Dada (2006); Kolo (2000) and Williams (2009), explain that the ideas behind residential schools which is the educational settings or environment meant strictly for training and provision of adequate and qualitative education, based on individual differences that exists among impaired persons is to ensure unhindered academicperformances and achievement for impaired persons. One lesson from this is that, It is not proper for mild, marginal, moderate, severe or profound impaired persons to be grouped within non-impaired group in the same learning environment. In addition, scholars such as Kunzweler (1979); Agulana (1993); Igwe (2003) and Howard (2004) believe that the recommendation of mainstreaming or integration approach to education is a strategy used by government to dulge away from the responsibility of providing more special schools, facilities and manpower for the education of exceptional people or the handicapped.

For the purpose of this study, mainstreaming education is therefore referes to as, the practice of educating mild impaired pupils in public lower basic three secondary schools together with non-impaired peers in the same school environment in northwest zone of Nigeria. Academic achievement is refers to as the end of third-term academic scores of both impaired and non-impaired pupils in English language,Mathematics and Social Studies (2011 / 2012). Mildly Impaired pupils refers to as lower basic three pupils that has mild visual, hearing, speech / language, learning and behaviour. Non-impaired pupils refers to pupils in lower basic three 
who has no impairments and disabilities and, Northwest Nigeria refers to Kano, Jigawa, Katsina, Kebbi, Zamfara, Sokoto and Kaduna states.

\section{Research Objectives}

The following research objectives were formulated for the study:

1. To determine whether there is a significant difference in English language academic achievement between mildlyimpaired and non-impaired pupils in northwest Nigeria.

2. To determine whether there is a significant difference in Mathematics academic achievement between mildly impaired and non-impaired pupils in northwest Nigeria.

3. To determine whether there is a significant difference in Social Studies academic achievement between mildly impaired and non-impaired pupils in northwest Nigeria.

4. To determine whether there is a significant difference in English language, Mathematics and Social Studies academic achievement between mildlyimpaired and non-impaired pupils in northwest Nigeria.

\section{Research Questions}

The following research questions were formulated for the study:

1. Is there a significant difference in English language academic achievement between mildly impaired and non-impaired pupils in northwest zone of Nigeria?

2. Is there a significant difference in Mathematics achievement between mildly impaired and non-impaired pupils in northwest Nigeria?

3. Is there a significant difference in Social Studies academic achievement between mildly impaired and nonimpaired pupils in northwest Nigeria?

4. To determine whether there is a significant difference in English language, Mathematics and Social Studies academic achievement between mildly impaired and non-impaired pupils in northwest Nigeria. ?

\section{Research Hypotheses}

The following null-hypotheses were formulated for the study:

1. There is no significant difference in the English language academic achievement between mildly impaired and non-impaired pupils in northwest zone of Nigeria.

2. There is no significant difference in the Mathematics academic achievement between mildly impaired and non-impaired pupils in northwest Nigeria.

3. There is no significant difference in the Social Studies academic achievement between mildly impaired and non-impaired pupils in northwest Nigeria.

4. There is no significant differnce in English language, Mathematics and Social Studies academic achievement between mildly impaired and non-impaired pupils in northwest Nigeria.

\section{Reseach Design}

\section{Methodology}

The research design adopted for this study was an Ex-post factor design. In the study, the design was used to gather evidences of varied mild impairments and disabilities which was then used to collect academic scores of both the impaired and non-impaired pupils in the study areas.

\section{Population}

The population comsisted of one million, one hundred and thirty-two thousand lower basic three secondary school pupils in Kano, Jigawa, Katsina, Kebbi, Zamfara, Sokoto and Kaduna states public schools (source: School Records, 2011/2012).

\section{Sample and Sampling Technique}

The sample consisted of two thousand four hundred and fourty-three impaired lower basic three public secondary school pupils. The mildly impaired pupils were identified by classroom teachers with the use of Prevalence of Varied Impairement / Disabilities and Academic Achievement Scale and two thousand four hundred and fouty-three non- impaired lower basic three public secondary school pupils, who were randomlly selected; given a total of two thousand eight hundred and eighty-six, spread across fifty-three schools in the study areas.

The sampling techniques used were purposive and simple random sampling techniques based on the nature of the investigation. 


\section{Data Collection Instrument}

The instrument used for this study was a 'Self-developed structure scale 'Prevalence of Varied Impairments / Disabilities and Academic Achievement Scale' (POVIDAAS). The scale consisted of four sections: section A: The personal data of the respondents, which comprised the name of the school and class level of the respondents. Section B: contained five mild impairments / disabilities and the identifying characteristics and Section C: contained ruled sheets for the supply of end of term academic scores in English language and Mathematics for both exceptional and non-exceptional pupils. And, section D: portion created for signature and official stamp of cooperating school teacher and official stamp of the cooperating school so as to ensure authenticity of the information provided.

\section{Validation of the research Instrument}

1. Validity: Content and face validitieswere used since the items selected were based on the review of literature and pilot study of the responses of experts in Special Education, Educational psychologists and Counselling psychologists in National Open University of Nigeria, Bayero University, Kano and Federal College of Education, Kano.

2. Reliability: The reliability of the academic achievement scores in were ensured by test developers of the states Educaational Resource Departments of the seven states used in the study. In addition, Score Transformation was used, the raw scores provided from the end of term academic achievement of the samples were transformed to Standard Scores before been analyzed. This process allowed the researchers to remove possible bias that may be due to markers subjectivities.

\section{Adminstration of Research Instruments}

The researchers administered the instruments through the use of Research assistants who were students undergoing courses in Special Education in Bayero University, Kano and Federal College of Eucation, Kano. The research assistants were given choices to select from the seven states that constituted the study areas. The period of data collection lasted for three months since time is not an hindering factor of influence to the study.

\section{Methods of Data Analysis}

The researchers employed both descriptive and inferential statistics for data analysis, t-test for independent samples and analysis of variance (Anova) were employed to test the research hypotheses at 0.05 level of significance. SPSS version 18.0 was utilized in the computation.

\section{The results of the study were presented below:}

\section{Results}

Hypothesis One: There is no significant difference in the English language academic achievement between mildly impaired and non-impaired lower basic three secondary school pupils in northwest Nigeria.

Table 1: t-test analysis of English language academic achievement of midly impaired and non-impaired

\begin{tabular}{|c|c|c|c|c|c|c|}
\hline \multicolumn{7}{|c|}{ Pupils ( $N=2886)$} \\
\hline \multirow{4}{*}{$\begin{array}{l}\text { Variables } \\
\text { English language } \\
\text { of mildly } \\
\text { impaired pupils. } \\
\text { English language } \\
\text { of non-impaired } \\
\text { pupils }\end{array}$} & Number & Mean & $\overline{\mathrm{Sds}}$ & $\mathrm{df}$ & t-calculated & t-critical \\
\hline & 2443 & 57.33 & 7.13 & & & \\
\hline & & & & 4884 & 9.00 & 1.96 \\
\hline & 2443 & 50.94 & 8.43 & & & \\
\hline
\end{tabular}

Table 1 shows the test for difference between the English language academic achievement of mildly impaired and non-impaired pupils. The analysis that a significant difference exists between the two groups since the calculated $t$ of 9.00 is greater than the $t$-critical of 1.96 .

Hypothesis 2: There is no significant difference in the Mathematics academic achievement between mildly impaired and non-impaired pupils in northwest Nigeria. 
Table 2: t-test analysis of Mathematics academic achievement of midly impaired and non-impaired

\begin{tabular}{|c|c|c|c|c|c|c|}
\hline \multicolumn{7}{|c|}{ Pupils ( $N=2886)$} \\
\hline $\begin{array}{l}\text { Variables } \\
\text { Mathematics of } \\
\text { mildly impaired } \\
\text { pupils }\end{array}$ & $\begin{array}{l}\text { Number } \\
2443\end{array}$ & $\begin{array}{l}\text { Mean } \\
56.95\end{array}$ & $\begin{array}{l}\text { Sds } \\
5.99\end{array}$ & $\mathrm{df}$ & t-calculated & t-critical \\
\hline $\begin{array}{l}\text { Mathematics of } \\
\text { non-impaired } \\
\text { pupils }\end{array}$ & & & & 4884 & 10.49 & 1.96 \\
\hline & 2443 & 50.97 & 7.81 & & & \\
\hline
\end{tabular}

Table 2 shows the test for difference between the Mathematics academic achievement of mildly impaired and non-impaired pupils. The analysis that a significant difference exists between the two groups since the calculated $t$ of 10.49 is greater than the t-critical of 1.96 .

Hypothesis Three: There is no significant difference in the Social Studies academic achievement between mildly impaired and non-impaired pupils in northwest Nigeria.

Table 3: t-test analysis of Social Studies academic achievement of mildly impaired and non-impaired

\begin{tabular}{|c|c|c|c|c|c|c|}
\hline \multicolumn{7}{|c|}{ Pupils $(\mathrm{N}=\mathbf{2 8 8 6})$} \\
\hline \multirow{4}{*}{$\begin{array}{l}\text { Variables } \\
\text { Social studies of } \\
\text { mildly impaired } \\
\text { pupils } \\
\text { Social Studies of } \\
\text { non-impaired } \\
\text { pupils }\end{array}$} & Number & Mean & $\mathrm{Sds}$ & $\mathrm{df}$ & t-calculated & t-critical \\
\hline & 2443 & 56.4 & 7.86 & & & \\
\hline & & & & 2884 & 6.57 & 1.96 \\
\hline & 2443 & 51.87 & 8.29 & & & \\
\hline
\end{tabular}

Table 3 shows the test for difference between the Social Studies academic achievement of exceptional and non-exceptional pupils. The analysis that a significant difference exists between the two groups since the calculated $t$ of 6.57 is greater than the $t$-critical of 1.96 .

Hypothesis Four: There is no significant differnce in English language, Mathematics and Social Studies academic achievement between mildly impaired and non-impaired pupils in northwest Nigeria.

Table 4: One -way Anova Comparison of Mean Academic Achievement ofEnglish language, Mathematics and Social Studies of mildly impaired and non-impaired Pupils ( $N=\mathbf{2 8 8 6})$

\section{Significant at 0.05 .}

\begin{tabular}{|llccc|}
\hline Source of Variation & df & SS & MS & F \\
Between Groups & 2 & 476.58 & 238.29 & 20.78 \\
Within Groups & & & & \\
Total & 2884 & 8237.39 & 11.49 & \\
\hline
\end{tabular}

Table 4 shows the test for difference between the English language, Mathematics and Social Studies academic achievement of mildly impaired and non-impaired pupils. The one way Analysis of Variance (ANOVA) reveales that a significant difference exists between the two groups since the calculated $\mathrm{F}$-ratio of 20.74 is greater than the F-value at 0.05 level of significance. The hypothesis was rejected indicating a significant difference in academic achievement of mildly impaired and non-impaired pupils.

\section{Discussion}

The study research hypotheses tested the significant difference between the English language academic achievement; Mathematics academic achievemnt; Social Studies academic achievemet ; and English language, Mathematics and Social Studies academic achievement of mildly impaired and non-impaired pupils in northwest Nigeria. The finding that there is a significant difference betweenthe English language academic achievement; Mathematics academic achievemnt; Social Studies academic achievemet; and English language, Mathematics and Social Studies academic achievement of exceptional and non-exceptional pupils in northwest Nigeria. These recorded significant differences in academic achievements between mildly impaired and non-impaired pupils supported the findings of Igwe (2003) that adolescents in mainstreaming education has 
many problems arising from physiological make-up, generation gap and sexuality.Also in agreement with Adam (2009) who is of the opinion that if investigations are conducted on the effect of mainstreaming education in Nigeria, a lot of revealations that will come out will make those in favour of such arrangement to have a rethink on the idea. In line with Olaleye (2010) who strongly condems the idea of integration of handicapped children with normal chldren and concludes that the arrangement was adopted by government only to reduce cost of public spending on the education of handicapped children which requireshuge investiment and commitments. Dada (2006) observations that exceptional pupils are unable to engage in all activities open to thier non-exceptional peers and these usually contributes to thier poor academic performance is held by the findings of this study. In the same view, Hechinger in Howard (2004) cautiones that mainstreaming education slowed down the bandwagon of instant change and the confusion between civil right and the right kind of education for every child. Nwokolo (2003) opines that successful uses of academic achievement records has be used to differenciate between properlly and non-properlly adjusted adolescents, this is also comfirmed by the findings of this study in identifying the difference between academic achievement of exceptional and nonexceptional pupils in northwest Nigeria. The findings are also in agreement with Abu (2011) beliefs that academic achievement records can be analyze to identify groups that are unequal based on predetermined criterion; Adepoju (2012) observes that a well documented academic achievement records of scores of learners' have been used to determine the success or failure of many educational programmes and policies in many parts of the world; Bichi (2009) opines that one of the most known formal criterial for evaluating whether learning as taken place among learners' is through the uses of academic performances and achievements. Yusuf (2012) beliefs that proper adjustment and successful academic achievement among learners' are indicators of successful teaching and learning. The use of three differents academic subjects in the study as academic achievement of comparison agrees with Smith (2010)who cautions that when using academic achievement to differenciate between groups and then advocates the use of combinations of differenct academic records that shows variations among learners is also held by the findings of this study.

\section{Conclusion}

Findings of this research comfirmed that there is a significant difference betweenthe English language academic achievement;; Mathematics academic achievemnt; Social Studies academic achievemet; and English language, Mathematics and Social Studies academic achievements of mildly impaired and non- impaired pupils under the mainstreaming learning environment in northwest Nigeria.

\section{Recommendations}

The presence of mildly impaired pupils (mild visual, hearing, speech / language, learning and behaviour) and the significant differences in academic achievements among mildly impaired when compared with non-impaired pupils in mainstreaming secondary schools in northwest Nigeria means that the physical envronment must now be constructed with the various categories of mildly impaired pupils in mind.Specialists in the education of mildly impaired pupils should be employed. Teachers should employed varied teaching methods and strategies to accormondate the various categories of pupils when teaching and teachers should also help the impaired pupils to reassess as well as reinforce thier goals, values and assets as well as reinforce thier efforts for better adjustment. Charitable organisations should also remember the mildly impaired in mainstreaming education by providing aids to enable them develop independence, academic performance, selfreliance. coping and adaptive skills.

\section{References}

[1]. Abang, T. B. (1886). Handbook of special education: Teaching the visually handicapped. Ibadan University.

[2]. Abu, J. P. (2011). The nature and needs of exceptional people. Kaduna. Hostin Publishers Limited.

[3]. Adepoju, J. O. (2004). Academic achievements are not enough. Handbook for teachers of visually Impaired. America Printing House.

[4]. Adima, E. E. (1989). Special education. Ibadan. Education Publishers.

[5]. Agulanna, G. G. (1993). Atitude of non-handicapped students toward thier handicapped school mates: Implications for school acceptance. Nigeria Journal of counselling and consulting Psychology, 2 (2) 42-48.

[6]. Bichi, M. Y. (200). Introduction to research and statistics. Debis-co Press and Publishing Company Limited.

[7]. Dada, R. M. (2008). Teaching strategies for the education of exceptional children. Debis-co Press \&Publishing Company Limited.

[8]. Dada, .R. M. (2006). Introduction to special education (1 st eds.). Debis-co Press \& Publishing Company Limited.

[9]. Federal Republic of Nigeria (2004). National Policy on Education. Lagos. Nigerian Educational Research and Development Council (NERDC).

[10]. Howard, S. (2004). Exceptional children. Columbus: Charles E. Merit.

[11]. Igboayaka, B. C. (1986). Problems and prospects of integrating handicapped students into the regular Secondary schools in Imo state. An unpublished M. Ed Thesis. Port Harcourt University.

[12]. Igwe, M. M. (2003). Adjustment problems of blind students in the integrated secondary schools. Nigeria Journal of Educational Psychologists 2 (1) 191.

[13]. Kolo, I. A. (2000). Outreach identification scheme for all gifted and talented persons: An eclectic model For Nigeria. In E. D. Ozoji \& I. K. 
[14]. Kunzweller, C. E. (1979). String mainstreaming will it work? Education, 99 (3) 235.

[15]. Nwokola, D. A. (2003). The influence of self-concept, school environment and gender on students' Psychological adjustment. Nigeria Journal of Counselling Development.

[16]. Olaleye, M. O. (2010). Limitations and advantages of blind integration insecondary schools in Oyo North Local government area of Oyo state. B. Ed Project. Kano. Federal College of Education.

[17]. Yusuf, K. (2012). Introduction to measurement and evaluation. Zaria. Tamaza Printing Press Limited. 